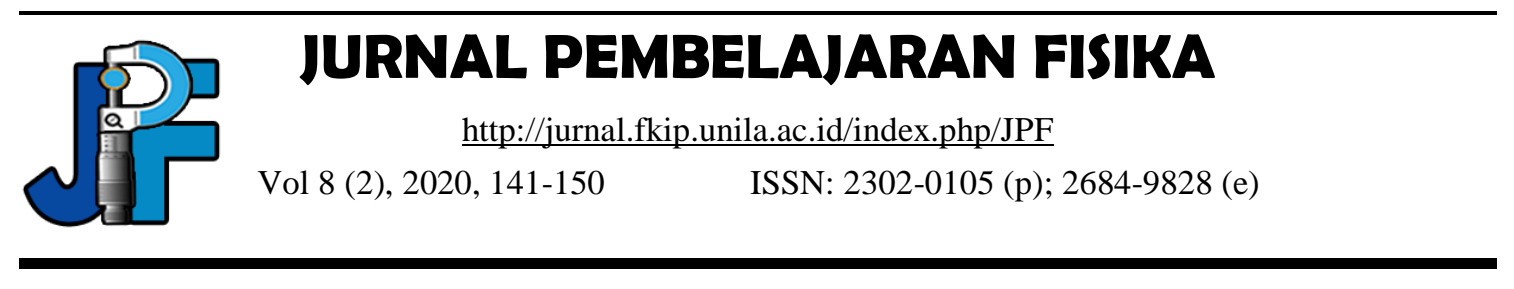

\title{
The Effect of GIL Assisted Phyphox in Physics Learning towards Creative Thinking
}

\author{
Firda Dwi Fatmala, Eko Suyanto, Ismu Wahyudi*, Kartini Herlina \\ Department of Physics Education, Lampung University, Indonesia \\ *e-mail: Ismuwahyudi@fkip.unila.ac.id
}

\begin{abstract}
This study aims to determine how the effect of the Phyphox application on GIL based physics learning on students' creative thinking abilities. The sample of this research is students of class X IPA 3 SMA Negeri 1 Sukoharjo through purposive sampling technique. This study uses the One Group Pretest-Posttest design. The treatment was carried out through GIL based practicum activities on a simple pendulum assisted by Phyphox application. Data on students' creative thinking abilities were obtained using tests in the form of description questions. Data analysis technique using Paired Sample T-test. Based on data analysis, the average score of creative thinking ability has increased by $44 \%$. Learning on simple pendulum materials assisted by Phyphox applications in five groups has an average acceleration due to gravity of $9,87 \mathrm{~m} / \mathrm{s}^{2}$ with an accuracy rate of $98,6 \%$. The result is that GIL based physics learning assisted with the Phyphox application affects students' creative thinking abilities and produces accurate investigative data.
\end{abstract}

Keywords: Creative Thinking Abilities, GIL, Online, Phyphox applications, Smartphone

DOI: http://dx.doi.org/10.23960/jpf.v8.n2.202002 


\section{INTRODUCTION}

The industrial revolution 4.0 presents new competition and challenges, so that education is expected to be able to prepare students to face global challenges. The National Research Council of The National Academies (2010) suggests that learning should be more emphasized on $21^{\text {st }}$ century skills, such as Critical Thinking, Creativity, Collaboration, and Communication. Through benchmarks of abilities that must be mastered in the 21 st century, learning outcomes will be assessed as more meaningful and competitive.

In fact, the average score of the National Examination in physics for SMA/MA/ SMK level in 2019 presented by the Ministry of Education and Culture (Kemendikbud) is the lowest than the other science subjects such as biology and chemistry. In fact, students' ability in the field of science in Indonesia is at the level of 62 out of 72 survey participating countries as seen from the competition held by the Program for International Student Assessment (PISA) in 2015. One of the aspects assessed by PISA is thinking ability. This problem is because physics investigations require students to carry out experiments in accordance with the laboratory instructor so that the data obtained is in accordance with the theory that makes students unable to develop their thinking skills (Liu et al., 2016). Thus, learning needs to facilitate students in training thinking skills that are able to cross the limits of their thinking or better known as creative thinking.

Responding to the Covid-19 pandemic, the government transferred learning to the online system (Kemendikbud No.4, 2020). Online learning is considered more suitable for students because in 2020 high school students are included in $\mathrm{Z}$ generation who were born in 1997-2012 who is fluent in the world of technology and its implementation in learning. Learning in generation $\mathrm{Z}$ is different from previous generations, where students prefer to discuss and learn online rather than face to face (Schwieger \& Ladwig, 2018). In addition, Turner (2015) said that generation $\mathrm{Z}$ is accustomed to do everything through portable smartphone devices. The characteristic of $\mathrm{Z}$ movement certainly does not prevent students from learning physics, including in their investigation. This result has been confirmed by Schauer et al. (2008) who states that distance learning and investigation can reduce cognitive load by supporting individual understanding processes and offering access to knowledge that makes students as adaptive individuals.

The result of a comparative study of data acquisition tools conducted by Liu et al. (2016) on smartphone, DV, and NXT won by smartphones as the most accurated dara producing devices. Previous research on the use of smartphone sensors on simple pendulum materials has also been conducted by Suciarahmat \& Yudhoko (2015) who investigated gravitational acceleration using an accelerometer application and produced a gravitational acceleration of $9,73 \mathrm{~m} / \mathrm{s}^{2}$. This application is considered inaccurated because it is not equipped with a remote control in the experiment such as a simple pendulum with a greater degree of accuracy. According to Staacks et al. (2018) the Phyphox application, which can be installed on smartphone devices, can be used in a variety of physics experiments that are more precise with the high level of data accuracy because it is assisted by many custom experiments and remote control access. The observation process assisted by the Phyphox application makes it easy for students to collect the data. So, number of quantitative researches can be done with a smartphone (Khun \& Vogt, 2013). 
Learning which utilizes access to hardware devices in learning activities is called multimedia learning (Nevid, 2012). According to Mayer (2005) humans have two different channels of information processing between visual and verbal, which are called dual coding theory. The two aspects between visual and verbal should be presented together so that knowledge can be well received in long-term memory (Clark \& Mayer, 2016). Each individual has different knowledge and memory storage capacities, whether the teachers or students. Social constructive theory views learning as a social process (McMahon, 1997). The social process will be established through small groups, so that it will succeed in facilitating learning through the social environment (Newman, 2005). Each study group will support each other, work together, share knowledge to achieve more meaningful learning goals. Small group learning can be implemented in discovery and investigation activities or it is called inquiry. Wenning (2010) states that the Guided Inquiry Laboratory (GIL) activity focuses on students as independent learners that conducting experiments through real-world phenomena. The problem questions given by the teacher at the GIL stage will respond to the students to carry out an investigation (Hendrickson, 2015). Through guided laboratory inquiry, it will produce higher quality and meaningful students' performance apart from other investigative activities (Kaltacki \& Oktay, 2011).

The purpose of this study was to describe the effect of the Phyphox application on GIL based physics learning on students' creative thinking abilities.

\section{METHOD}

This research was conducted at SMA Negeri 1 Sukoharjo in 2020 even semester online. In this study, there are two forms of variables, namely the independent variable and the dependent variable. The independent variable in this study is the GIL assisted Phyphox application and the dependent variable is the student's creative thinking ability. This study used an experimental class with the selection of the research sample using purposive sampling technique. Learning is carried out with the help of the Phyphox application with GIL stages.

\section{Research Design \& Procedures}

This study used the One Group Pretest-Posttest design by giving pretest before treatment and posttest after treatment. The analysis value from the pretest and posttest will get the results of how the effect of tretment on learning.

\section{Population and Sample}

The population and sample in this study were selected using purposive sample technique. The population in this study were all students of class X IPA at SMA Negeri 1 Sukoharjo, namely X IPA 1, X IPA 2, X IPA 3, X IPA 4 and X IPA 5. The sample obtained was one class, namely X IPA 3 based on the value of learning outcomes, the value of students activeness in participating in online learning, and this class has the most respondents who master the electronic devices needed in the study. The number of respondents was 29 students who were then carried out sampling until 18 students were obtained as respondents based on their consent to participate in the study, ownership of laptops, smartphones and networks that support learning. 


\section{Data Collection and Instrument}

The instrument used in this study was a written test instrument with a total of 7 items describing creative thinking skills with a Cronbach alpha value of 0.73 .

\section{Data Analysis}

The increase of the pretest and posttest scores can be seen by performing the $\mathrm{N}$ gain data analysis technique for the creative thinking ability on indicators of fluency, flexibility, originality, and elaboration. Samples that have been normally distributed are used to see the effect of learning treatment with Paired Sample T-test analysis.

\section{RESULT AND DISCUSSION}

The average value of students 'creative thinking abilities increased after being given treatment in the form of learning assisted by the GIL assisted Phyphox application which can be seen in Figure 1. Based on these results it is known that the average increase in students' creative thinking skills in the posttest is greater than in the pretest.

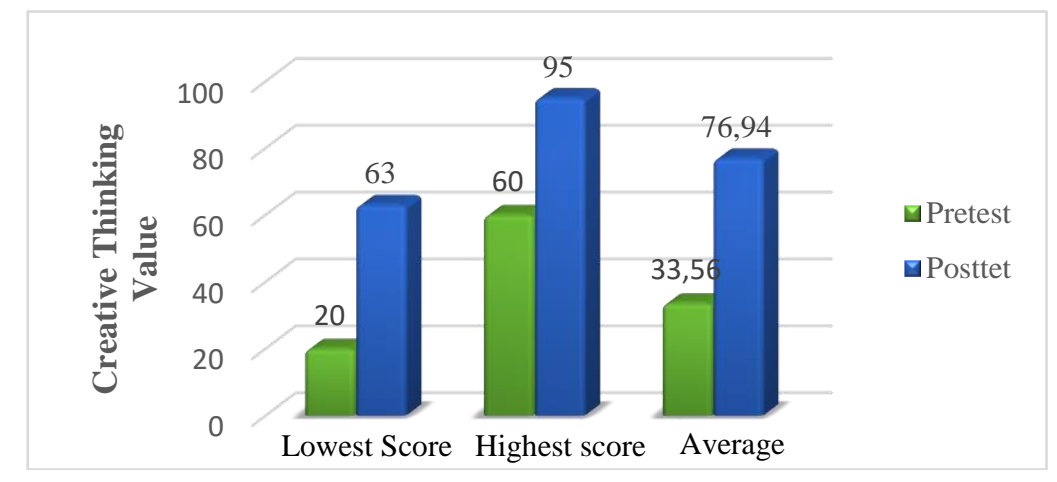

Figure 1. Average Students' Creative Thinking Ability

The average results of the ability to think creatively on each indicator can be seen in Figure 2.

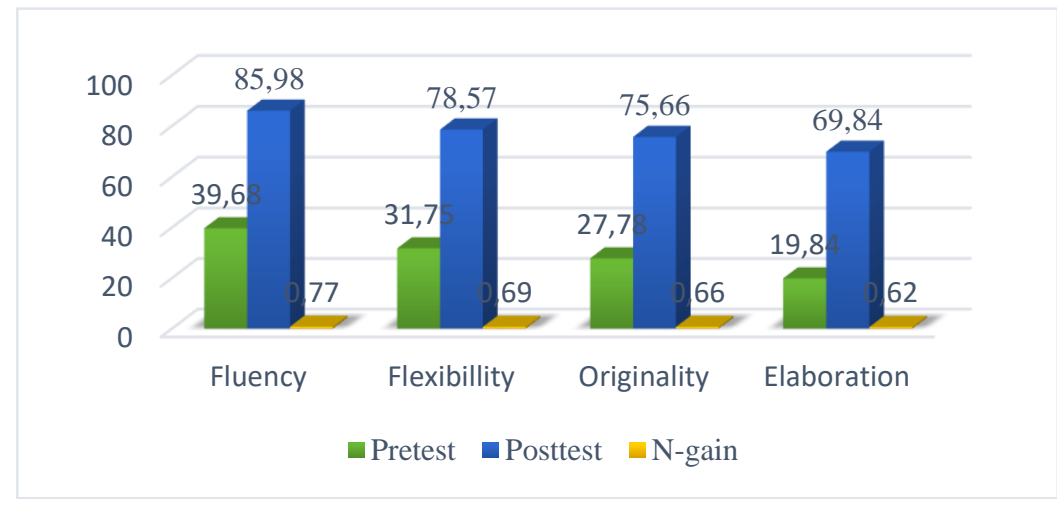

Figure 2. Average Creative Thinking Ability

Based on Figure 2, it is known that the indicator of the ability to think fluently or fluency is an indicator of the ability to think creatively which is the highest controlled by 
students. Hypothesis testing is carried out using students' N-gain data. The average pretest and posttest $\mathrm{N}$-gain data can be seen in Table 1 .

Table 1. $N$-gain Creative Thinking Ability

\begin{tabular}{lccccc}
\hline $\begin{array}{c}\text { Acquisition } \\
\text { Score }\end{array}$ & Pretest & Posttest & N-gain & $\begin{array}{c}\text { Increment } \\
\%\end{array}$ & $\begin{array}{c}\text { Category N- } \\
\text { gain average }\end{array}$ \\
\hline Highest Score & 60 & 95 & 0.88 & $55 \%$ & High \\
Lowest Score & 20 & 63 & 0.54 & $35 \%$ & Moderate \\
\hline Average & 33.55 & 77 & 0.67 & $44 \%$ & Moderate \\
\hline
\end{tabular}

Seen in table 1 that, it is known that the average increase in students' creative thinking skills in the postest is higher than in the pretest. The average $\mathrm{N}$-gain result of students' creative thinking ability is in the medium category. The pretest and posttest $\mathrm{N}$ gain data were used to test the hypothesis. Before testing the hypothesis the data were normally distributed.

The result of the T-test showed a sig.2-tailed value $<0.05$ with a significance level of 5\% which states that GIL based treatment or learning assisted by the Phyphox application has an influence on students' creative thinking abilities.

The average of the results of the simple pendulum investigation carried out in the five groups obtained a gravitational acceleration of $9.87 \mathrm{~m} / \mathrm{s}^{2}$, a relative error of $1.39 \%$ with a tolerance for decision making of $5 \%$ and a data accuracy rate of $98.6 \%$. So it can be said that simple pendulum learning assisted by the Phyphox application produces data with a high degree of accuracy. This result has also been communicated by Staacks, et al. (2018) which states that the Phyphox application facilitates students in many physics experiment activities and produces more accurate data.

Based on the result of the homogenety test, it shows that there is an average defference in the ability to think creatively before and after learning assisted by the Phyphox application. Phyphox application assisted learning provides information both visually and verbally. According to Mayer (2005) in dual coding theory states that information storage is divided into two channels, namely visual and verbal, which, if presented in a relevant way, can optimize students storing information or knowledge in long-term memory. Learning that emphasizes problem solving and student independence to be active finds it very suitable if it is taught in accordance with guided laboratory inquiry learning. According to Wenning (2010) Guided Inquiry Laboratory or (GIL) is an advanced pedagogical practice generally consisting of students who more or less independently develop and implement experimental plans and collect data so that students can develop their thinking skills which can be trained in the learning process. GIL is considered as another form of problem based learning or PBL which emphasizes activities in small groups (Newman, 2005). The learning process that occurs in small groups in online learning does not prevent students from communicating to achieve common goals. When conducting remote investigations, each group can be connected easily through face-to-face applications such as zoom and WhatsApp so that cooperation between group members and teachers or with other groups continues to run conditionally and only requires a fairly short study time so it is considered more efficient. This result has also been said by Schwieger \& Ladwig (2018) that students as a characteristic of generation $\mathrm{Z}$ prefer to online learning. The result of Purwaningsih, Rosidin, \& Wahyudi (2017) also 
konfirm that face to face learning accompanied by online learning result in more meaningful learning.

The stages of guided laboratory inquiry learning that are directly oriented to investigations assisted by the Phyphox application are located at the generalization stage which plays a role in all indicators of creative thinking abilities. According to (Alburaie \& Daniel, 2014) the ability to think creatively can be measured by 4 aspects, namely fluency, flexibility, originality, and ellaboration. In the process of investigating, students are faced with a track of the objects they observe on a laptop as a remote control, which is where students' ability to think smoothly is trained. This investigation process will usually find inappropriate gravitational acceleration values and non-sinusoidal graphs if the investigation procedure is not in accordance with procedures such as angles that are not a requirement for harmonic vibrations, less precise rope installation, inhomogeneous rope length and careless pendulum deviations. Students will be accustomed to using many ideas to solve a problem in this process and expressing ideas whether it is a question or problem solving solution according to the ability to think fluently that this indicator can be said to be successfully mastered if students are able to solve problems through ideas, questions, ideas, and solutions solving the problem from previously observed evidence.

Indicators of creative ability in the flexible thinking aspect, students will be faced with various data and must be processed in the microsoft excel program . Students will be trained to have flexible or flexible abilities with activities to group data, convert units, and values from frequencies into periods or vice versa. Grouping data in the form of data tabulation and arriving at the graph plot of the manipulation variable relationship to the response variable that students are investigating is a form of student activity to master indicators of flexible thinking ability. According to Desmarais (2012) the indicator of the ability to think flexibly can be seen when students are able to solve problems both in the phenomena of images, tables and graphics. Student activities that practice flexible thinking skills can be seen in Figure 3 as follows.

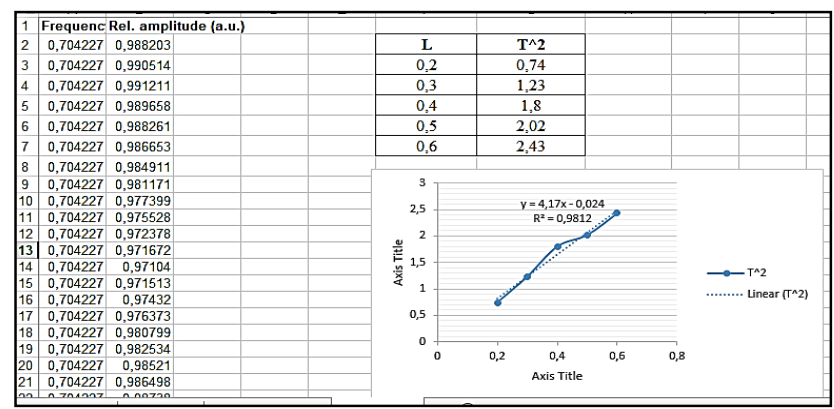

Figure 3. The process of tabulating the results of investigation data assisted by the Phyphox application

Indicators of creative ability in the aspect of original thinking, students are given the freedom to make experimental design designs independently based on investigative procedures in accordance with the examples that the teacher has presented in the practicum manual and learning videos. The results of the investigations that have been carried out obtained a different design in each group. This result has been said by Haris \& Bruin (2018) which states that the ability to think creatively is not only seen from new 
results but is also able to generate new ideas by combining, changing, or re-applying existing ideas. The sample design tool design in the two groups can be seen in Figure 4 as follows.

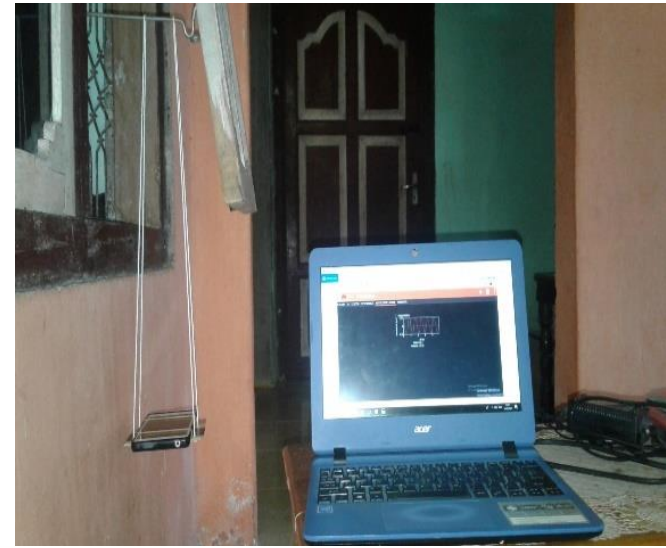

(a)

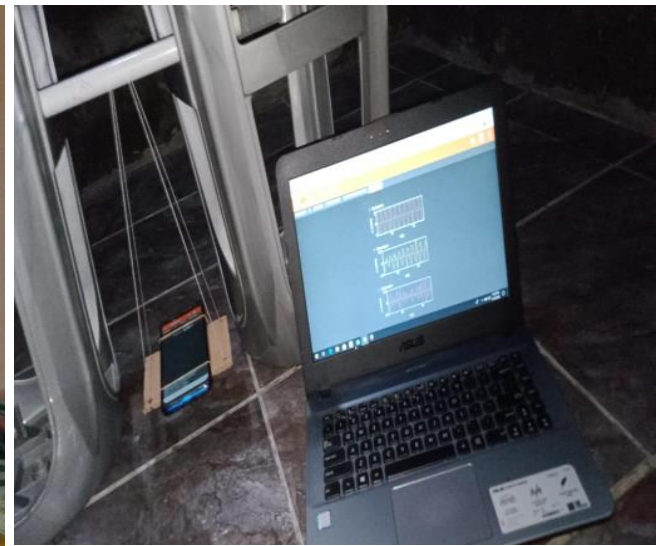

(b)

Figure 4. (a) \& (b) A series of simple pendulum experiments assisted by the Phyphox application

Indicators of creative thinking ability in the detailed thinking aspect, students are trained to analyze experimental data to find the equation of the pendulum period. After the tabulation the data is converted into a graph, a linear regression equation will be obtained from the length of the rope to the period. The straight line equation obtained on the graph is then analyzed in detail using dimensional analysis to find out what quantities affect the pendulum period other than the length of the rope. The results of the analysis will in detail obtain the equation, the Relative Error obtained, to see the average gravitational acceleration based on the data they obtain. The process that trains detailed thinking can be seen in the picture 5 as follows.
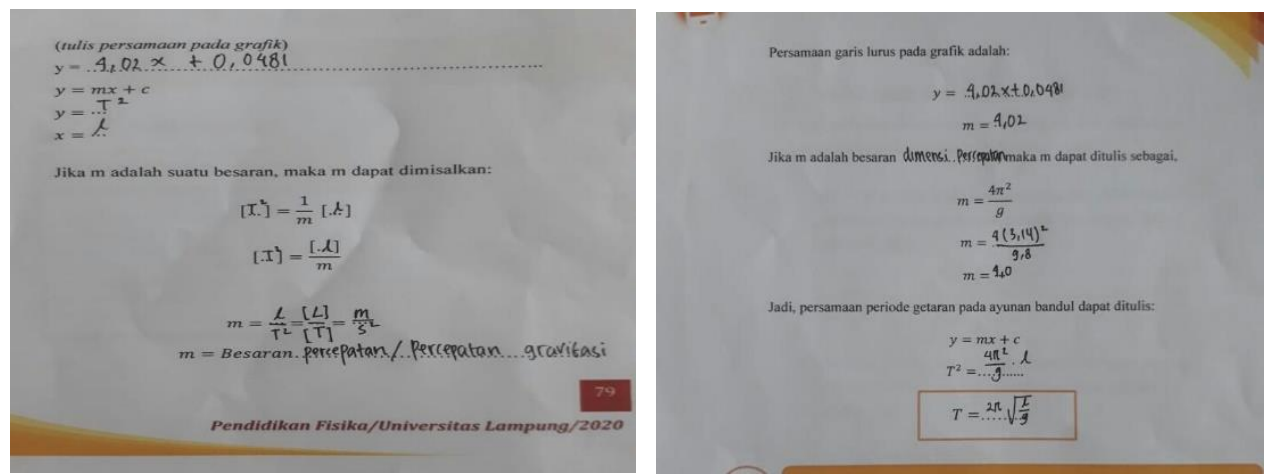

Figure 5. Student activity in detailing knowledge

Based on the picture 5 everything in the process will train students to have the ability to think in detail if students are able to solve problems beyond their thinking limits. This result has also been said by Desmarais (2012) who revealed that creative thinking is the result of someone who has applied logical principles, after a lot of investigation and analysis to solve problems with high-level innovation, different thinking and taking risks 
as evidence that they have mastering knowledge by crossing the boundaries of the field of science.

Based on Figure 2, the average creative thinking ability, Fluency is the ability to interpret various problems or evidence either in the form of an image or video with ideas that produce appropriate solutions from what they observe. The fluency indicator gets an average value of 85.59. The ability to think fluently is high because students have been able to provide various problem solving solutions from what they have observed correctly because the questions of creative thinking skills presented are equipped with relevant narration, pictures and videos. This result has been communicated by (Mayer, 1989: Mayer \& Gallini, 1990) in Clack \& Mayer (2016) states that students who read text containing illustrations placed near the appropriate word will produce about $65 \%$ more useful solutions on subsequent problem-solving tests than simply reading text without illustrations. Sumardani et al. (2020) also say that visual assisted learning improves higher-order thinking. Therefore, students find it easier to solve the questions given. In addition, students are also trained to think fluently because the learning process is carried out online which requires them to understand a narrative along with supporting pictures and video instructions, both in the investigation module assisted by the Phyphox application or the LKPD they are working on. The activities in the learning process train students to express ideas about a problem smoothly by finding solutions and ideas for solving problems correctly according to what they observe.

The ability on the indicator of elaboration shows the lowest creative thinking ability with an average value of 69.84. As the lowest indicator controlled by students, it can be seen that some students did not solve the problem in detail on each given question. During the learning process, especially the data analysis process to detailed activities such as analyzing linear regression equations on graphs to finding the value of a quantity, to finding equations, which should be a learning process that trains students to solve a problem in detail, in fact many students do not take part or browse online tutorials. So that in one group consisting of only 3-4 students who really follow the learning process until the application. After the detailed thinking questions the teacher gives back to the students in the posttest it can be observed that students who actively participate in learning, guidance and discussion in their groups can answer problem solving in the detailed thinking section of the problem well.

\section{CONCLUSION}

Based on the paired sample T-test, it was found that the average difference in creative thinking abilities before and after learning using the Phyphox application. Increasing the ability to think creatively in Simple Harmonic Motion on the pendulum with the help of the GIL based Phyphox application can train creative thinking on fluency, flexibility, originality, and elaboration indicators of students with good categories.

\section{REFERENCES}

Alburaie, F., \& Daniel, Esther. GS. (2014). Developing a Creative Thinking Test For Iraqi Physics Students. International Journal of Mathematics and Physical Sciences Research. 2(1), 80-84. 
Clark, CC \& Mayer, RE . (2016). E-learning and the Science of Instruction: Proven Guidelines For Consumers and Designers of Multimedia Learning (second edition). San Francisco: John Wiley \& Sons.

Desmarais, Serge. (2012). Changing Lives Improving Lives. Canada: University Guelph.

Harris, Anne \& Bruin. Leon R.de. (2018). Training Teachers For Twenty-First Century Creative And Critical Thinking: Australia Implications From an International Study. Journal of Teaching Education. 29(3), 234-250.

Hendrickson, Tamara. L. (2015). Integrating Responsible Conduct of Research Education into Undergraduate Biochemistry and Molecular Biology Laboratory Curricula. Biochemistry and Molecular Biology Education. 43(2), 68-75.

Kaltakci, Derya \& Oktay, O. (2011). A Guided Inquiry Laboratory Experiment To Reveal Students' Cimprehension Of friction Concept: A Qualitative Study. Balkan Physics Letters. 19, 180-190.

Kemendikbud. (2019). Laporan Hasil Ujian Nasional SMA/MA tahun pelajaran 2019/2020. Diakses dari https://hasilun.puspendik.kemdikbud.go.id/.

Kemendikbud. (2020). Surat Edaran Menteri No. 4 tahun 2020. diakses dari jdih.kemendikbud.go.id.

Kirraly, Don. (2014). A Social Constructivist Appoach to Translator Education. London \& New York: Routledge Taylor \& Francis Group. 215 p.

Kuhn, Jochen, \& Vogt, Patrik. (2013). "Application and Examples of Experiments with Mobile Phone and Smartphone in Physics Lessons". Frontiers in Sensors. 1 (4), 67-73.

Liu, Chia-Yu., Chao-Jung Wu., Wing-Kwong Wong., Yunn-Wen Lien., \& Tsung-Kai Chao. (2016). Scientific Modeling With Mobile Devices In High School Physics Labs. Journal of Computer \& Education. 105, 44-56.

Mayer, Richard. E. (2005). A Cognitive Theory of Multimedia Learning. The Cambridge handbook of Multimedia Learning. 41, 31-48.

McMahon, M. (1997). Social Constructivism and the World Wide Web-A Paradigm for Learning. Paper Presented at the ASCILITE conference. Pert, Australia. Vol (327).

National Research Council (NRC). (2012). Education for Life and Work: Developing Transferable Knowledge and Skills in the 21st Century. Washington, DC: The National Academis Press.

Nevid, Jefferey. S. (2012). Psychology Concept and Applications: fourth edition. USA Jon-David Hague.

Newman, Mark. J. (2005). Problem Base Learning: An Introduction and Overview of the Key Features of the Approach. Journal of Veterinary Medical Education. 32 (1), 12-20.

OECD. (2018). PISA 2015 Results in Fokus. Downloaded from https://www.oecd.org/pisa / pisa-2015-results-in-focus.pdf. 
Purwaningsih, R., Rosidin, U., \& Wahyudi, I. (2017). Pengaruh Penggunaan E-learing Dengan Schoology Terhadap Hasil Belajar Peserta Didik. Jurnal Pembelajaran Fisika, 5(4).

Schauer, F., Ozvoldova, M., Lustig, F., \& Dekar, M. (2008). Real Remote Mass-Spring Laboratory Experiments Across Internet-Inherent Part Of Integrated E-Learning Of Oscillations. International Journal of Online and Biomedical Engineering (iJOE), 4 (1).

Schwieger, D \& Ladwig, C. (2018). Reaching and Retaining the Next Generation: Adapting to the Expectations of the Gen $\mathrm{Z}$ in the Classroom. Information Systems Education Journal. 16 (3), 45

Staacks, S., S, Huutz., H, Heinkel, \& C Stampfer. (2018). Advanced Tools For Smartphone-Based Experiments: Phyphox. Physics Education. 53 (4), 045009.

Suciarahmat, A \& Y, Pramudya. (2015). Aplikasi Sensor Smartphone dalam Eksperimen penentuan Percepatan Gravitasi. Jurnal Fisika Indonesia. 19(55), 1410-2994.

Sumardani, D., Putri, A., Ramadhan, Z., Bakri, F., \& Muliyati, D. (2020). Augmented Physics' Lab: Magnetic Field Use Virtual Learning Media for 21st Century Students. Jurnal Pembelajaran Fisika, 8(1), 61-70.

Turner, Anthony. (2015). Generation Z: Technology and Social Interest. Journal of Individual Psychology. 71(2), 103-111.

Wenning, Carl. J. (2010). Levels of inquiry: Using inquiry spectrum learning sequences to teach science. Journal of Physics Teacher education. 5(4), 11-20. 